\title{
PERAN TERAPI MUSIK TERHADAP KESEJAHTERAAN JANIN DI PUSKESMAS KENDAL KEREP MALANG
}

\author{
Jiarti Kusbandiyah ${ }^{1,}$ Shinta Astriani ${ }^{2}$ \\ ${ }^{1}$ Prodi Kebidanan STIKES Widyagama Husada, Malang \\ email : jia sutanto@yahoo.co.id \\ 2Prodi Kebidanan STIKES Widyagama Husada, Malang \\ email : shinta.astriani11@gmail.com
}

\begin{abstract}
The percentage of growth retardation and development of children is estimated between $4 \%$ $8 \%$ in developed countries and $6 \%-30 \%$ in developing countries. The provision of early childhood stimulation can begin when the child is still in the womb in order to avoid delays in fetal growth and development by conducting music therapy to the fetus. Based on the preliminary study conducted in in March, 2014, in Public Health Center Kendal Kerep Malang, therewere 60 - 70 pregnant women in one month who checked their pregnancy there. It was known also that Public Health Center Kendal Kerep implemented the program of music therapy in pregnant women and mothers at labor. This study aimed at finding out the effect of music therapy for the fetal welfare in Public Health Center Kendal Kerep Malang.

The research method used was pre-experimental research using one group pre-test-post-test design. The purposive sampling was used to the pregnant women whose pregnancy was $\geq 16$ weeks.In Public Health Center Kendal Kerep Malang there were 15 respondents who met the inclusion criteria. To analyze the data, Paired Sample T-test was used. The result of this research showedthere were 9 respondents (60\%) who were in fair category dealing with the assessment of fetal movement. Whereas Fetal Heart Rate measurement showed that 15 respondents (100\%) were normal. Based on the result of Paired Sample T test analysis, itwas concluded that there is a significant effect before and after the treatment of music therapy for the fetal welfare. It is suggested for health workers, especially midwives to improve the quality of health services and knowledge about music therapy for the fetal welfare.
\end{abstract}

Keywords : fetal movement, FHR measurement, music therapy 


\begin{abstract}
ABSTRAK
Angka kejadian keterlambatan pertumbuhan dan perkembangan anak diperkirakan antara $4 \%$ - $8 \%$ pada negara maju dan $6 \%$ - 30\% pada negara berkembang.Pemberian stimulasi dini pada anak bisa dimulai saat anak masih dalam kandungan agar tidak terjadi keterlambatan pertumbuhan dan perkembangan janin yaitu dengan pemberian terapi musik pada janin. Berdasarkan hasil studi pendahuluan yang dilakukan pada bulan Maret 2014 pada Puskesmas Kendal Kerep kota Malang terdapat 60 - 70 ibu hamil dalam 1 bulan yang memeriksakan kandungannya. Diketahui juga bahwa Puskesmas Kendal Kerep pernah menerapkan program terapi musik pada ibu hamil dan pada ibu saat persalinan.

Penelitian ini bertujuan untuk mengetahui pengaruh terapi musik terhadap kesejahteraan janin.Metode penelitian yang dilakukan di Puskesmas Kendal Kerep kota Malang ini menggunakan Pra Experiment dengan desain penelitian one group pre-test-post-test. Sampel yang digunakan adalah ibu hamil dengan usia kehamilan $\geq 16$ minggu di Puskesmas Kendal Kerep kota Malang yang memenuhi kriteria inklusi yaitu 15 responden. Teknik sampling yang digunakan adalah teknik purposive sampling. Analisa data dari penelitian ini yaitu menggunakan uji statistik Paired Sample T-test.Hasil dari penelitian ini adalah terdapat 9 responden atau sebesar $60 \%$ responden dengan hasil penilaian gerakan janin kategori cukup, sedangkan hasil pengukuran DJJ dari 15 responden ( $100 \%$ ) adalah normal. Berdasarkan hasil uji statistik Paired Sample T test menunjukan bahwa ada pengaruh yang signifikan sebelum dan setelah pemberian terapi musik terhadap kesejahteraan janin.Disarankan bagi tenaga kesehatan terutama bidan untuk meningkatkan mutu pelayanan kesehatan dan pengetahuan tentang terapi musik terhadap kesejahteraan janin.
\end{abstract}




\section{PENDAHULUAN}

Upaya mewujudkan pembangunan sumber daya manusia di Indonesia mengalami suatu kendala yaitu adanya keterlambatan pertumbuhan dan perkembangan anak. Angka kejadian keterlambatan pertumbuhan dan perkembangan anak diperkirakan antara $4 \%-8 \%$ pada negara maju dan $6 \%-30 \%$ pada negara berkembang. Data angka kejadian keterlambatan pertumbuhan dan perkembangan umum belum diketahui secara pasti, namun diperkirakan sekitar $1 \%-3 \%$ anak di bawah usia 5 tahun mengalami keterlambatan perkembangan umum. Biasanya anak dengan keterlambatan pertumbuhan dan perkembangan mempunyai nilai IQ di bawah 70 dan nilai EQ mengikuti nilai IQ, jika nilai IQ di bawah normal atau di bawah 70 maka nilai EQ juga di bawah normal atau terhambat (Saputra, 2013).

Penyebab terjadinya keterlambatan pertumbuhan dan perkembangan anak dikelompokan menjadi tiga ( 3 ) meliputi : 1) Keadaan sebelum lahir berasal dari gizi ibu hamil terutama dalam trimester akhir kehamilan akan mempengaruhipertumbuhan janin, posisi janin yang abnormal bisa menyebabkan cacat kongenital, radiasi atau paparan radium dan sinar rontgen dapat menyebablainan pada janin, faktor gizi dan nutrisi ibu saat hamil, obat - obatan yang dikonsumsi ibu saat hamil misalnya pemakaian kortikosteroid jangka lama akan menghambat pertumbuhan janin, faktor psikologis ibu hamil contohnya stres ibu hamil akan memberikan dampak negatif terhadap pertumbuhan dan perkembangan janin dalam kandungannya, 2) Keadaan saat kelahiran seperti komplikasi persalinan pada bayi seperti trauma kepala, asfiksia dapat menyebabkan kerusakan otak, rangsangan atau stimulasi berperan penting pada pertumbuhan bayi, 3) Keadaan setelah persalinan antara lain gizi untuk tumbuh kembang bayi, penyakit kronis atau kelainan kongenital misalnya tuberkolosis, anemia, kelainan jantung bawaan mengakibatkan retardasi pertumbuhan (Ronald, 2010).

Upaya yang dilakukan untuk menekan terjadinya keterlambatan pertumbuhan dan perkembangan anak dapat dilakukan dengan tindakan flashback dari keadaan saat ibu hamil yaitu dengan dilakukan pemeriksaan tinggi fundus uteri.Pemeriksaan USG diperlukan untuk mengukur pertumbuhan janin dan dapat juga digunakan untuk melihat kelainan organ yang terjadi. Pemantauan gerakan janin, pemantauan denyut jantung janin dengan doppler, melakukan penilaian biofiskal seperti penilaian gerakan pernafasan janin, interpretasi Non Stress Test dan Contraction Stress Test merupakan teknik - teknik observasi pertumbuhan dan perkembangan janin. (Cunningham, 2005)

Salah satu cara efektif bertujuan untuk memberi stimulasi dini pada janin agar tidak terjadi keterlambatan pertumbuhan dan perkembangan janin yaitu dengan pemberian terapi musik pada janin. Faktor biologis dan fisiologis bayi dapat dibentuk sejak janin masih dalam kandungan.Suara ibu dan musik klasik memberi pengaruh rasa nyaman pada janin yang mendengarnya termasuk ibu yang mengandungnya. Kondisi ini mempengaruhi janin untuk tumbuh dan berkembang dalam suasana yang relatif tenang sehingga proses perkembangannya berlangsung optimal. (Musbikin, 2009)

Terapi musik adalah materi yang mampu mempengaruhi kondisi seseorang baik fisik maupun mental.Musik memberi rangsangan pertumbuhan fungsi - fungsi otak seperti fungsi ingatan, belajar, mendengar, berbicara serta analisi intelek dan fungsi kesadaran.Musik memberi nuansa yang bersifat menghibur, menumbuhkan suasana yang menenangkan dan menyenangkan 
seseorang, sehingga musik tidak hanya berpengaruh terhadap kecerdasan berfikir saja tetapi juga kecerdasan emosi. (Djohan, 2005)

Stimulasi musik, terutama musik klasik, bisa mulai diberikan sejak janin berusia empat bulan karena pada masa ini, janin menjalani proses pembentukan sel sel otak dan pada usia tersebut janin diperkirakan sudah mampu memberikan respons terhadap suara. Stimulasi melalui musik klasik sebaiknya dilakukan setiap hari, minimal setengah jam atau 30 menit. Diperkirakan proses pembelajaran pada janin di dalam kandungan terjadi melalui neurotransmitter lewat darah ibu. (Musbikin, 2009)

Di Indonesia penelitian tentang terapi musik sudah mulai dikembangkan.Terapi musik mulai dilakukan sebagai salah satu pengobatan di Rumah Sakit anak Bangsa Harapan Kita Sumatera Utara. Khususnya di Medan Gleni Internasional Hospital melakukan kelas prenatal tiga kali dalam satu minggu dengan jumlah peserta dalam satu group sebanyak $14-16$ orang ibu hamil,mayoritas ibu hamil dengan kehamilan trimester III. Hasil riset menunjukkan bahwa pelatihan dengan musik memberi lebih dari sekedar hubungan sebab akibat terhadap perkembangan bagian - bagian tertentu dari otak janin secara jangka panjang(Nurwahid, 2012).

\section{METODE PENELITIAN}

Jenis penelitian ini adalah Pra Experiment dengan desain atau rancangan penelitian one group pre-test-post test,dilakukan untuk menjelaskan seberapa peran terapi musik untuk kesejahteraan janin. Responden diperdengarkan music selama kurang lebih 30 menit kemudian dilihat perbedaan kesejahteraan janin sebelum dan sesudah diberikan terapi musik. Musik yang digunakan adalah musik klasik. Data diambil dengan menggunakan lembar observasi. Sampel adalah 15 ibu hamil di
Puskesmas kendalkerep dengan teknik purposive sampling.Variabel dianalisis secara deskriptif dan secara analitik menggunakan paired t-test.

\section{HASIL DAN PEMBAHASAN}

Penelitian dilaksanakan mulai bulan april sampai awal agustus 2014. Responden dalam penelitian ini adalah ibu hamil fisiologis. Setelah dilakukan pengkajian karakteristik dasar kehamilan responden didapatkan bahwa 86,7\% adalah kehamilan multigravisa dan sisanya adalah primigravida. $80 \%$ responden merupakan kehamilan trimester 2 dan sisanya kehamilan trimester 3. Hal ini berarti bahwa gerakan janin sudah dirasakan dan mudah dideteksi pada usia kehamilan tersebut. Gerakan janin mudah dideteksi untuk multigravida pada usia kehamilan 16 minggu dan primigravida pada usia 18 minggu. Karakteristik lain yang menunjukkan kehamilan fisiologis adalah TFU antara 20-30 cm, artinya besarnya sesuai dengan usia kehamilan responden.

Data khusus dalam penelitian ini meliputi gerakan janin dan denyut jantung janin sebagai parameter dari kesejahteraan janin. Berikut hasil distribusi frekuensinya dan analisisnya.

Tabel 1. Perbedaan Gerak Janin Kunjungan I di PuskesmasKendal Kerep kota Malang pada bulan Juni 2014

\begin{tabular}{lcc}
\hline \multirow{2}{*}{ Nilai Statistik } & \multicolumn{2}{c}{ Gerak Janin } \\
\cline { 2 - 3 } & Sebelum & Setelah \\
\hline Mean & 1,73 & 3,20 \\
Modus & 2 & 4 \\
Median & 2 & 4 \\
Standard Deviasi & 0,884 & 1,082 \\
\hline
\end{tabular}

Uji Paired Sampel T test Pvalue $(0,000)$

Sumber : Data Primer, 2014Berdasarkan table 1 dapat diketahui bahwa nilai mean atau nilai rata - rata gerak janin sebelum pemberian terapi adalah 1,73 dan mengalami peningkatan setelah pemberian terapi musik yaitu menjadi 3,20. Hasil uji paired sample $\mathrm{T}$ test menunjukkan bahwa Pvalue $(0,000)<\alpha(0,05)$ sehingga ada 
pengaruh terapi musik terhadap gerak janin.

Tabel 2.Perbedaan Gerak Janin Kunjungan II di Puskesmas Kendal Kerep kota Malang pada

bulan Juni 2014

\begin{tabular}{llc}
\hline \multirow{2}{*}{ Nilai Statistik } & \multicolumn{2}{c}{ Gerak Janin } \\
\cline { 2 - 3 } & Sebelum & Setelah \\
\hline Mean & 2,07 & 3,33 \\
Modus & 2 & 4 \\
Median & 2 & \\
Standard Deviasi & 0,884 & \\
\hline
\end{tabular}

Uji Paired Sampel T test Pvalue $(0,000)$ Sumber : Data Primer, 2014Hasil menunjukkan bahwa mayoritas frekuensi pergerakan janin sebelum pemberian terapi musik adalah $<4$ dan berdasarkan tabel 2 menunjukkan bahwa penilaian gerakan janin dalam waktu 30 menit adalah kurang. Nilai mean (rata-rata) gerakan janin sebelum pemberian terapi 2,07 meningkat setelah pemberian terapi musik menjadi 3,33, nilai standard deviasi juga mengalami peningkatan dari 0,884 menjadi 1,047 setelah pemberian terapi musik. Hasil uji paired sample $\mathrm{T}$ test menunjukkan bahwa Pvalue $(0,000)<a(0,05)$ sehingga asa pengaruh terapi musik terhadap gerak janin.

Berkurangnya gerakan janin dapat disebabkan oleh beberapa faktor antara lain (1) Usia kehamilan seperti yang dikatakan oleh Timor Tisch bahwa berkurangnya aktivitas pada janin mungkin berhubungan dengan waktu janin tidur, yang bertambah dengan makin maturnya janin. (2) Aktifitas ibu dan waktu penelitian juga sangat mempengaruhi gerakan janin seperti yang diungkapkan oleh dr. Kartiwa Hadi Nuryanto (2010) bahwa gerakan janin akan terasa apabila janin bergerak aktif, biasanya janin akan bergerak aktif setelah ibu makan atau pada saat malam hari. Pada pagi atau siang hari, gerakan janin akan kurang terasa karena kesibukan ibu.(3) Ibu tertidur saat janin aktif bergerak.
Setelah pemberian terapi musik mayoritas gerakan janinnya adalah cukup (4gerakan) dan mengalami peningkatan. Peningkatan gerak janin pada penelitian ini terjadi karena janin merespon rangsangan dari luar kandungan berupa suara musik ataupun suara percakapan ibu dan peneliti. Hal ini sesuai dengan teori bahwa janin usia 16 minggu mulai bisa mendengar suara - suara dari luar tubuh ibunya. Hal ini bisa diфuktikan dengan cara ibu mengajak jani,04 bicara ataupun memperdengarkan musik. Sebagai reaksi, janin akanbergerak yang menandakan otaknya dapat menerima rangsangan dari luar. Namun, tidak semua jenis musik cocok untuk janin, misalnya musik yangberirama cepat seperti rock, disko, dan rap. Musik yang terlalu keras justru akan membuat suasana janin tidak nyaman, tegang dan gelisah. Jenis musik yang dianjurkan adalah musik yang berirama lembut dengan nada yang teratur(Djohan, 2005).

Respon yang diberikan oleh ibu setelah pemberian terapi musik adalah ibu merasa tenang dan rileks, dari keadaan ibu yang demikian bisa memberikan respons yang positif terhadap janin sehingga gerakan janin bisa bertambah atau meningkat hal ini sesuai dengan manfaai terapi musik menurut Musbikin (2009) yaitu manfaat yang pasti dirasakan setelah melakukan terapi musik adalah perasaan rileks, tubuh lebih bertenaga dan pikiran lebih fresh. Terapi musik memberikan kesempatan bagi tubuh dan pikiran untuk mengalami relaksasi yang sempurna selain itu terapi musik dapat membantu ibu - ibu hamil agar tetap dapat mempertahankan keseimbangan antara kesehatan jasmani, pikiran, dan emosi.

Berdasarkan penelitian ini dapat diketahui bahwa ada perbedaan yang signifikan pergerakan janin sebelum dan setelah pemberian terapi musik. Dalam penelitian ini gerak janin dibagi menjadi 3 ( tiga ) tiga kategori baik (> 4 gerakan), 
cukup (4 gerakan), dan kurang ( $<4$ gerakan).

Sebelum pemberian terapi musik nilai mean 1,73 dengan gerak janin cenderung kurang $(<4$ gerakan), gerakan janin berkurang bisa disebabkan karena beberapa faktor antara lain usia kehamilan ibu pada saat penelitian yang sudah matur atau aterm.

Menurut Timor Tisch (2008) bahwa berkurangnya aktivitas pada janin mungkin berhubungan dengan waktu janin tidur, yang bertambah dengan makin maturnya janin atau bertambahnya usia kehamilan. Selain usia kehamilan aktifitas dan kondisi ibu juga berpengaruh terhadap gerakan janin, semakin ibu sibuk gerakan janin akan semakin sulit dirasakan oleh ibu, hal ini sesuai dengan yang dikatakan oleh dr. Kartiwa Hadi Nuryanto (2010) gerakan janin akan terasa apabila janin bergerak aktif, biasanya janin akan bergerak aktif setelah ibu makan atau pada saat malam hari. Pada pagi atau siang hari, gerakan janin akan kurang terasa karena kesibukan ibu dan karena kesibukan tersebut ibu akan merasa kelelahan sehingga ibu sulit pula untuk merasakan gerakan janinnya.

Setelah pemberian terapi musik nilai mean meningkat menjadi 3,20 dengan gerakan janin cenderung cukup (4 gerakan) meskipun beberapa responden gerakan janinnnya masih kurang. Peningkatan gerakan janin ini menandakan bahwa janin menerima respon dari luar kandungan berupa suara musik sesuai dengan teori bahwa janin merespon suara - suara dari luar kandungan ibunya dengan gerakan menendang - nendang ( Djohan, 2005 ). Ketenangan ibu dan ketelitian ibu dalam merasakan gerakan janinnya penting untuk dilakukan. Ketenangan ibu pada saat penelitian ini sangat berpengaruh terhadap gerakan janin, ibu yang tenang atau rileks gerakan janinnya cenderung bertambah dibandingkan dengan ibu yang kurang rileks pada saat penelitian.
Tabel 3.Perbedaan Frekuensi DJJ Kunjungan I di Puskesmas KendalKerep Kota Malang pada bulan Juli 2014

\begin{tabular}{ccc}
\hline \multirow{2}{*}{ Nilai Statistik } & \multicolumn{2}{c}{ Frekuensi DJJ } \\
\cline { 2 - 3 } & Sebelum & Setelah \\
\hline Mean & 137,53 & 140,93 \\
Modus & 138 & 138 dan 142 \\
Median & 138 & 142 \\
Standard & 3,292 & 3,990 \\
Deviasi & & \\
\hline
\end{tabular}

Uji Paired Sample T test Pvalue $(0,001)$

Sumber : Data Primer, 2014

Berdasarkan tabel 3 dapat diketahui bahwa nilai mean atau rata - rata frekuensi djj sebelum pemberian terapi musik adalah 137,53 dan setelah pemberian terapi musik meningkat menjadi 140,93 . Hasil uji paired sample $T$ test menunjukkan bahwa Pvalue $(0,001)<\alpha(0,05)$ sehingga ada pengaruh terapi musik terhadap frekuensi djj.

Tabel 4.Perbedaan Frekuensi DJJ Kunjungan II di Puskesmas Kendal Kerep kota Malang pada bulan Juni 2014

\begin{tabular}{ccc}
\hline \multirow{2}{*}{ Nilai Statistik } & \multicolumn{2}{c}{ Frekuensi DJJ } \\
\cline { 2 - 3 } & Sebelum & Setelah \\
\hline Mean & 136,27 & 141,47 \\
Modus & 136 dan 138 & $142,144,146$ \\
Median & 137 & 142 \\
Standard & 3,826 & 3,739 \\
Deviasi & & \\
\hline
\end{tabular}

Uji Paired Sample T test Pvalue $(0,000)$

Sumber : Data Primer, 2014

Berdasarkan hasil penelitian terhadap 15 ibu hamil usia kehamilan $\geq 16$ minggu di Puskesmas Kendal Kerep kota Malang tentang frekuensi djj sebelum pemberian terapi musik selama 1 menit pada kunjungan I dan II dapat diketahui bahwa pengukuran frekuensi djj dari 15 responden $(100 \%)$ adalah normal (120-160 kali/menit). Keadaan normal tersebut dipengaruhi oleh kondisi ibu yang rileks dan emosi ibu yang stabil pada saat penelitian.

Setelah pemberian terapi musik terjadi beberapa peningkatan denyut jantung janin namun peningkatan tersebut masih dalam batas normal. 
Wicaksono (2012) menyatakan bahwa saat mendengarkan musik, otak memproses apa yang didengar, detak jantung cenderung mengikuti atau sinkron dengan kecepatan musik. Saat mendengar musik dengan tempo yang rendah, detak jantung akan melambat dan tubuh akan menjadi rileks. Keadaan rileks ini akan memperlancar sirkulasi darah ibu dan janin melalui plasenta. Denyut jantung janin akan mengikuti sinkronasi dengan denyut jantung ibu sebagai sumber musik pertama yang janin dengar dalam kandungan. Akan tetapi dalam penelitian ini setelah pemberian terapi musik yang berirama lambat frekuensi denyut jantung janin cenderung meningkat. Peningkatan denyut jantung janin ini terjadi karena setelah pemberian terapi musik ibu dalam keadaan yang kurang rileks dan ibu merasa kecapaian sehingga akan mempengaruhi frekuensi denyut jantung janin.

Berdasarkan hasil penelitian ini dapat diketahui bahwa ada perbedaan yang signifikan sebelum dan setelah pemberian terapi musik dalam waktu 1 menit. Dalam penelitian ini frekuensi djj dibagi dalam 3 (tiga) kategori yaitu normal (120-160 kali/menit), takikardi (160-180 kali/menit), dan bradikardi (100-120 kali/menit).

Berdasarkan tabel 4 dapat diketahui bahwa nilai mean ( rata-rata ) frekuensi djj sebelum pemberian terapi musik yaitu 136,27 dan meningkat setelah pemberian terapi musik menjadi 141,47. Hasil uji paired sample $\mathrm{T}$ test menunjukkan bahwa Pvalue $(0,000)<$ a $(0,05)$ sehingga ada pengaruh terapi musik terhadap frekuensi DJJ.

Sebelum pemberian terapi musik mayoritas frekuensi djj adalah normal (120$160 \mathrm{kali} /$ menit) dengan nilai rata - rata djj 137,53 karena pada saat penelitian mayoritas responden dalam kondisi sehat dan rileks. Kondisi ibu yang sehat, rileks dan emosi ibu yang stabil mempengaruhi frekuensi denyut jantung janin jika kondisi ibu pada saat penelitian berlangsung kurang rileks, kurang sehat seperti demam, dan emosi ibu kurang stabil kemungkinan akan terjadi takikardi.

Setelah pemberian terapi musik frekuensi denyut jantung janin cenderung meningkat. Hal tersebut tidak sesuai dengan teori yang menyatakan bahwa saat mendengarkan musik, otak memproses apa yang didengar, detak jantung cenderung mengikuti atau sinkron dengan kecepatan musik. Saat mendengar musik dengan tempo yang rendah, detak jantung akan melambat dan tubuh akan menjadi rileks. Keadaan rileks ini akan memperlancar sirkulasi darah ibu dan janin melalui plasenta. Denyut jantung janin akan mengikuti sinkronasi dengan denyut jantung ibu sebagai sumber musik pertama yang janin dengar dalam kandungan. Keseimbangan ini harus dijaga dari stress, baik fisik maupun psikis agar janin tidak mengalami gangguan pertumbuhan selama dalam uterus dan tidak menjadi penyulit bagi ibu hamil selama kehamilan hingga persalinan. (Wicaksono, 2012).

\section{KESIMPULAN DAN SARAN}

Sebelum pemberian terapi musik, gerakan janin cenderung kurang $(<4$ gerakan) rata-rata gerakan janinnya 1,73 dan frekuensi denyut jantung dalam keadaan normal (120-160 kali/menit) ratarata frekuensi djj 137,53.Setelah pemberian terapi musik gerakan janin cenderung meningkatmenjadi cukup (4 gerakan) ratarata gerakan janinnya 3,20 dan frekuensi denyut jantung janin cenderung bertambah namun tetap konstan dan dalam keadaan normal (120-160 kali/menit) rata-rata frekuensi djj 140,93.Ada perbedaan yang signifikan antara frekuensi gerak janin sebelum dan setelah pemberian terapi music dan ada perbedaan yang signifikan antara frekuensi denyut jantung janin sebelum dan setelah pemberian terapi musik. Saran yang disampaikan adalah 
petugas kesehatan dan ibu hamil mulai membiasakan diri untuk memberikan terapi musik terhadap bayinya sejak dini dan secara teratur.

\section{DAFTAR PUSTAKA}

Cunningham, F. Gary. 2005. Obstetri Williams. Jakarta : EGC. Retrieved at March 14, 2014.

Djohan. 2005. Terapi Musik, Teori dan Aplikasi. Yogyakarta : Galangpress

Ronald, H.S 2010.Pedoman dan Perawatan Kehamilan yang Sehat dan Menyenangkan.Bandung : nuansa Aulia

Musbikin, Imam. 2009. Kehebatan Musik untuk Mengasah kecerdasan Anak.Yogyakarta : IHDINA

Nurwahid, Ahmad. 2012. Pengaruh Mendengarkan Musik Klasik terhadap Perkembangan Otak Bayi.Retrieved at March 11, 2014.

Saputra, Helmi. 2013. Nilai Keterlambatan Pertumbuhan dan Perkembangan Anak Berdasarkan IQ dan EQ.

Wicaksono, Muhammad. 2012. Artikel Pengaruh Musik Bagi Tumbuh Kembang Janin Dalam Kandungan. 